\title{
Effect of thermo-physical properties of cooling mass on hybrid cooling for lithium-ion battery pack using design of experiments
}

\author{
Ravichandra Rangappa ${ }^{1}\left[\right.$ ] $\cdot$ Srithar Rajoo ${ }^{1}$
}

Received: 31 May 2018 / Accepted: 4 September 2018 / Published online: 10 September 2018

(c) The Author(s) 2018

\begin{abstract}
The environmental and sustainability issues related to fossil fuel have made electric vehicles an alternative solution with lithium ion (Li-Ion) as the energy source. The sensitive nature of Li-Ion batteries has led to an active research on their thermal management for the past decade. The rise in temperature in Li-Ion batteries involves complex dynamics and there are several approaches to control it. Keeping it as the focus of research, this paper illustrates the application of design of experiments (DOE) to optimize the control variables involved in thermal management. Control variables used for optimization are mass of phase change material (PCM), thermal conductivity of paraffin copper composite (PCC) and water flow rate (WFL). The influence of these variables on the temperature rise of Li-Ion batteries has been studied. The research methodology involved full factorial DOE with two replications to analyze the influence of temperature control parameters of Li-Ion batteries. Multivariate analysis involved analysis of variance (ANOVA) that was used to test the hypotheses, which included the first and second-order interaction effect of control variables. The hypothesis testing has revealed that all the variables of study had a significant influence on the temperature rise of the Li-Ion batteries. The outcome of this research will be useful for Li-Ion battery manufacturers, as it provides suggestions to design appropriate cooling systems for the battery pack.
\end{abstract}

Keywords Battery thermal management system · Lithium-ion batteries · Design of experiments $\cdot$ Battery temperature . Hybrid electrical vehicles

\section{List of symbols}

$T$

F

$L$

$m$

$n$

$N$

$k_{\text {eff }}$

$k_{\mathrm{pcm}}$

$k_{\text {metal }}$

$\alpha$

$\varepsilon$

Ravichandra Rangappa

ravichandrra@yahoo.com

Srithar Rajoo

srithar@fkm.utm.my

1 UTM Center for Low Carbon Transport (LoCARtic), University Technology Malaysia, Skudai, Johor, Malaysia
Ambient temperature $\left({ }^{\circ} \mathrm{C}\right)$

Number of factors

Number of levels

Number of variant groups compared

Number of replications

Total number of experiment trials

Effective thermal conductivity (W/m K)

Thermal conductivity of pure PCM

(W/m K)

Thermal conductivity of metal (W/m K)

Critical value for $P$ under ANOVA (0.05)

Porosity

$\begin{array}{ll}\text { List of abbreviations } \\ \text { 2S10P } & \begin{array}{l}\text { 2-Series and 10-parallel architecture (bat- } \\ \text { tery cell/module) }\end{array} \\ \text { 6P10S } & \begin{array}{l}\text { 6-Parallel and 10-series architecture (bat- } \\ \text { tery cell/module) }\end{array} \\ \text { ADC } & \text { Analog to digital conversion } \\ \text { Adj_SS } & \text { Adjusted sum of squares } \\ \text { Adj_MS } & \text { Adjusted mean square } \\ \text { ANOVA } & \text { Analysis of variance } \\ \text { AWG } & \text { American wire gauge } \\ \text { BEV } & \text { Battery electrical vehicle } \\ \text { BTMS } & \text { Battery thermal management system } \\ \text { C-rate } & \text { Rate of discharge current } \\ \text { CC } & \text { Constant current } \\ \text { CR } & \text { Constant resistance } \\ \text { CV } & \text { Constant voltage } \\ \text { CW } & \text { Constant wattage } \\ \text { DOE } & \text { Design of experiments } \\ \text { DoF } & \text { Degree of freedom } \\ \text { Li-Ion } & \text { Lithium ion } \\ \text { LiCoO } & \text { Lithium cobalt oxide } \\ \text { Li(NiMnCo)O } & \text { Lithium nickel manganese cobalt oxide } \\ \text { LiMPO } & \text { Lithium metal phosphate }\end{array}$




$\begin{array}{ll}\text { MS } & \text { Mean square } \\ \text { NI } & \text { National Instruments } \\ \text { NIST } & \begin{array}{l}\text { National Institute of Standards and } \\ \text { Technology }\end{array} \\ \text { PHEV } & \text { Plug-in hybrid electrical vehicle } \\ \text { PCM } & \text { Phase change material } \\ \text { PCC } & \text { Paraffin-copper composite } \\ \text { PVDF } & \text { Polyvinylidene difluoride (membrane) } \\ \text { RSM } & \text { Response surface modeling } \\ \text { SOC } & \text { State of charge } \\ \text { SOH } & \text { State of health } \\ \text { Seq_SS } & \text { Sequential sum of squares } \\ \text { Temp } & \text { Battery temperature } \\ \text { WFL } & \text { Rate of water flow }\end{array}$

\section{Introduction}

The trend of plug-in hybrid electrical vehicles (PHEV) and battery electrical vehicles (BEV) is emerging in the automotive industries to address the environmental and sustainable issues [1]. Among all the rechargeable batteries, lithium-ion (Li-Ion) batteries have high energy density and a better cycle life [2], resulting in more attention from the researchers [3]. In hybrid and electrical vehicle applications, $\mathrm{Li}(\mathrm{NiMnCo})$ $\mathrm{O}$ and $\mathrm{LiMPO}$ in addition to $\mathrm{LiCoO}$ are popular as cathode material, due to their high energy density [4]. Li-Ion batteries are reported to be sensitive to the operating temperature. Further, internal degrading of cathode material is cited as the major reason for battery failure. Ramadass et al. conducted a capacity fade test for Sony's LiCoO cell, when cycled at various operating temperatures. They identified that the loss of $\mathrm{Li}$ under $\mathrm{LiCoO}$ caused the capacity fade at temperatures more than $50{ }^{\circ} \mathrm{C}$ [5]. Similar experiments conducted by other researchers on thermal runaway and capacity fade have rendered similar conclusions [6]. Thus, controlling the operating temperature for better performance and health of Li-Ion batteries is crucial. To achieve a balance between the performance and life of lithium batteries, it is important that the batteries are maintained between 0 and $40{ }^{\circ} \mathrm{C}$ temperature and the temperature distribution among cells below $5^{\circ} \mathrm{C}$ [7]. The state of health (SOH), life span and performance of Li-Ion batteries is dependent on temperature, as high temperatures can result in thermal runaway and degradation of cell material [8]. Li-Ion battery's nature of sensitivity is highly associated with its state of charge (SOC). Past research works have developed mathematical models to simulate the heat generation rate of a Li-Ion cell. The overall heat generated comprises Joule heating and entropy change during the charge and discharge cycles $[9,10]$. It is noticed from the mathematical models, low SOC has higher impact on heat generation and subsequently on the temperature rise of a battery cell. A dynamic measurement of accurate and reliable SOC and an efficient battery thermal management (BTMS) for a battery system used for PHEV and BEV are most essential to maintain the health, life and safety of LiIon battery.

Various types of BTMS have been proposed by researchers in the past. A computational simulation study for a battery pack with a number of cylindrical cells illustrated the control of temperature under air cooling. However, they failed to maintain the temperature distribution [11]. Under active air cooling, for a lower temperature rise, either a higher rate of air flow and a high frequent reversal of air flow are essential or the cooling has to be switched to liquid cooling $[12,13]$.

Fins were introduced to enhance the temperature uniformity under air cooling and such fins have shown an improved performance [14]. A metal foam in the air channel, along with fin pins to enhance thermal conductivity, also had a positive impact on temperature uniformity $[15,16]$. However, all these experiments were tried under low discharge rates. The heating plate cool pipe concept proposed for air/liquid cooling was not practically applicable, since it demanded a high utilization of copper that may lead to an increase in weight and cost for larger battery packs [17, 18]. Some of the research works proposed for liquid cooling with mini-channels [19-21] are not suitable for cylindrical or pouch cells, since the liquid channels fail to have contact surface with the cells' body. Moreover, fabrication of such mini- and micro-channels would be complicated and expensive. A similar case with micro-channeled cooling plate was proposed by An et al. [22]. The coolant flow needs to be more for discharge rates higher than $5{ }^{\circ} \mathrm{C}$, which could create high pressure within the cooling channels seeking a highpower pump.

The introduction of PCM-based passive cooling for $\mathrm{Li}$ Ion batteries has achieved a better control on temperature rise and temperature uniformity among the cells [23, 24]. A PCM material with a melting point below $45{ }^{\circ} \mathrm{C}$ has shown the best performance [25]. Although pure PCMbased cooling is simple and effective in controlling the temperature rise, it is inefficient in dissipating the heat [26]. Due to the lack of thermal conductivity, the heat generated during repeated cycles of charging and discharging would get locked within the PCM mass. To enhance the thermal conductivity temperatures, $\mathrm{PCM}$-graphite composites were introduced instead of pure PCM [27, 28]. Metal foam with pure PCM was tested by considering copper and aluminum as metals [29, 30]. Most of the earlier research works tested for a $10 \mathrm{Ah}$ battery cell with a maximum of $5 \mathrm{C}$ discharge. Although PCM-metal composites provide better cooling under low-capacity cells, they may not be efficient if the demand for power increases.

According to the current battery trends, Z-fold pouch cells have shown higher heat dissipation and thereby a high 
performance in comparison to cylindrical and prismatic cells [31]. In case of prismatic and pouch cells, the thermal conductivity is lower in the direction of thickness, and is higher in the direction of length and width. Thus, the cooling applied should be in the direction of length and width for a better temperature distribution [32]. A list of Li-Ion batteries suitable for hybrid and electric vehicle applications are listed in Table 1. During their full capacity discharge, the amount of heat generated will be substantially higher than any experiments and simulations presented in the literature. Thus, it requires a highly effective cooling mechanism, which has sufficient scope for extending its future performance.

A hybrid cooling technique with PCM and air/liquid is the current trend in the battery thermal management. Heat dissipation can be increased as well as controlled effectively by using air/liquid channels through the PCM mass. A numerical analysis on PCM-air hybrid cooling system for a Li-Ion battery pack was first proposed by Fathabadi. In his work, air ducts of rectangular cross section were inserted into the PCM cooling mass [38]. Similarly, Bai et al. proposed a unique method in which the bottom two-thirds of the Li-Ion battery cell was cooled by PCM and the top one-third by liquid cooling channel [39]. Hybrid cooling system comes with more control parameters that could assist in designing an appropriate cooling system for the battery pack by considering the ambient and working temperature. The present work is focused on hybrid cooling system applied to a battery pack with Li-Ion pouch cells. The application considered is for high-performance electric and hybrid electric vehicles. A parametric analysis is carried to study the various design parameters by applying the statistical design tool. and performance. The design parameters and their range values were selected for developing a linear regression model on the basis of the review of previous works. The hybrid cooling system depends on various design parameters, such as mass of PCM, thermal conductivity of the paraffin-metal composite and rate of coolant flow, type of coolant, and type of PCM. All these parameters have a high influence in controlling the temperature rise and maintaining uniform heat distribution and cooling rate of battery cells. The type of PCM and the coolant were maintained as constant for the present work, and the design parameters considered for experimentation and linear regression modeling are:

1. Mass of PCM, which varies with thickness of PCM, used between two consecutive Li-Ion cells.

2. Thermal conductivity of PCC, which varies as per the varying number of copper tubes.

3. Rate of water flow (WFL) is varied by controlling the flow of water through the copper tubes.

The effect of the above-mentioned parameters on LiIon's battery temperature and uniform heat distribution is observed in various studies. However, the interaction effects were independently presented by these studies and were not studied in a systematic way by applying statistical methods. The main objective of the present work is to develop a novel hybrid cooling system for a Li-Ion battery pack used in high-performance electric and hybrid cars. Battery pack is expected to maintain an operating temperature at various ambient temperatures. Thus, the interaction effect of various design factors on battery temperature is investigated by applying the principles of DOE.

\section{Objectives of research}

The selection of the design parameters for a hybrid cooling system and the decision of their values were the important factors in establishing control over the battery's temperature

Table 1 Advanced Li-Ion battery cells of current generation

\begin{tabular}{|c|c|c|c|c|c|}
\hline \multirow[t]{2}{*}{ Li-Ion cell supplier } & \multirow[t]{2}{*}{ Cell type } & \multirow{2}{*}{$\begin{array}{l}\text { Pouch size }(\mathrm{mm}) \\
W \times L \times T\end{array}$} & \multirow{2}{*}{$\begin{array}{l}\text { Ampere } \\
\text { rate }(\mathrm{Ah})\end{array}$} & \multicolumn{2}{|c|}{ Max discharge rate } \\
\hline & & & & Continuous & Pulse \\
\hline \multirow[t]{3}{*}{ Kokam [31] } & SLPB120216216 & $226 \times 227 \times 12$ & 53 & $5 \mathrm{C}$ & $8 \mathrm{C}$ \\
\hline & ${\text { SLPB } 120216216 H R 2^{a}}^{a}$ & $226 \times 227 \times 12.5$ & 47 & $12 \mathrm{C}$ & $18 \mathrm{C}$ \\
\hline & SLPB100216216H & $226 \times 227 \times 10$ & 40 & $8 \mathrm{C}$ & $15 \mathrm{C}$ \\
\hline Farasis [33] & IMP06160230P25A & $161 \times 230 \times 6$ & 25 & $4 \mathrm{C}$ & $7 \mathrm{C}$ \\
\hline XALT energy [34] & F940-0001 ${ }^{\text {b }}$ & $225 \times 225 \times 9.7$ & 37 & $8 \mathrm{C}$ & $16 \mathrm{C}$ \\
\hline EiG energy [35] & ePLBC037 & $224 \times 130 \times 12.6$ & 37 & $5 \mathrm{C}$ & $10 \mathrm{C}$ \\
\hline Tenergy [36] & 30123 & $157 \times 59.5 \times 9.8$ & 10.5 & $5 \mathrm{C}$ & $10 \mathrm{C}$ \\
\hline Targray [37] & Lithium-ion pouch ${ }^{\mathrm{b}}$ & $249 \times 155 \times 12$ & 44 & $3 \mathrm{C}$ & $10 \mathrm{C}$ \\
\hline
\end{tabular}

${ }^{a}$ Nanotechnology imbibed

${ }^{\mathrm{b}} 4 \mathrm{C}$ charging rate capable 
Table 2 Chemical composition of Li-Ion battery

\begin{tabular}{lll}
\hline Composition & Molecular formula & $\begin{array}{l}\text { Weight } \\
\text { percentage } \\
(\%)\end{array}$ \\
\hline $\begin{array}{l}\text { Lithium nickel cobalt manganese } \\
\text { oxide }\end{array}$ & $\mathrm{Li}\left[\mathrm{NiCoMn}_{2}\right]_{2}$ & $30-38$ \\
Carbon (such as graphite) & $\mathrm{C}$ & $18-20$ \\
PVDF & - & $1.1-2.0$ \\
Lithium hexafluorophosphate & $\mathrm{LiPF} 6$ & 2.0 \\
Aluminum & $\mathrm{Al}$ & $3.5-4.0$ \\
Copper & $\mathrm{Cu}$ & 8.0 \\
Organic carbonate & - & 13.0 \\
Plastic & - & 7.0 \\
\hline
\end{tabular}

Table 3 Characteristics of Li-Ion battery

\begin{tabular}{lllc}
\hline Parameter & Cell value & Module & EV pack \\
\hline Nominal voltage (VDC) & 3.7 & 37 & 370 \\
Maximum voltage (VDC) & $4.2 \pm 0.03$ & 42 & 420 \\
Minimum voltage (VDC) & $3.0 \pm 0.03$ & 30 & 300 \\
Capacity (Ah) & 10 & 20 & 120 \\
Max charge rate @ 2C (A) & 20 & 40 & 240 \\
Max continuous discharge @ & 100 & 200 & 1200 \\
$\quad$ 10C (A) & & & \\
Power (kW) & 0.3 & 6 & 360 \\
Energy (kWh) & 0.03 & 0.60 & 36 \\
Thickness (mm) & 9 & $\sim 170$ & \\
Width (mm) & 66 & $\sim 155$ & \\
Height (mm) & 156 & $\sim 165$ & \\
Number of cells & 1 & 20 & 1200 \\
Operating temperature & -10 to $45^{\circ} \mathrm{C}$ & \\
\hline
\end{tabular}

\section{Details of experimentation}

The present work is focused on Li-Ion batteries used for motor-driven vehicles. Li-Ion cells with higher charge/ discharge rate were selected for the thermal management testing. Specification and composition of the Li-Ion cell and module considered in the present work are listed in Tables 2 and 3. Under 10 Ah capacity, each cell is capable of discharging at a $10 \mathrm{C}$-rate with $100 \mathrm{~A}$ output at minimum 3 V. Battery module shown in Fig. 1 has 20 Li-Ion cells with 2S10P architecture and is capable of discharging up to $20 \mathrm{~A}$ at $30 \mathrm{~V}$ and an energy density of $600 \mathrm{Wh}$ with a total power rate of $6 \mathrm{~kW}$. Such ten modules connected in series would discharge $20 \mathrm{~A}$ at $300 \mathrm{~V}$, producing $60 \mathrm{~kW}$ power with $6 \mathrm{kWh}$ of energy, which is sufficient for any hybrid vehicle [40]. Energy required by an electric car to drive a range of $1 \mathrm{~km}$ is approximately $0.2 \mathrm{kWh}$ [41]. To power a high-performance electric car, 60 modules connected in $6 \mathrm{P} 10 \mathrm{~S}$ producing $120 \mathrm{~A}$ at $300 \mathrm{~V}$ with an energy of $36 \mathrm{kWh}$ would be required, which can haul a range of approximately $200 \mathrm{~km}$.

The entire experimentation was carried out in two stages as shown in Experimentation flowchart (Fig. 2). Under Stage-1, preliminary experiments were conducted using a battery module considering two cooling mechanisms. A pure PCM cooling with $10 \mathrm{~mm}$ PCM thickness between consecutive Li-Ion cells (Fig. 3a) was conducted. Subsequently, experiments were conducted for hybrid cooling system with four capillary copper tubes of size 3/16 inch inserted into the PCM cooling mass (Fig. 3b), with water circulation of $2 \mathrm{~L} /$ min flow rate. Stage-2 experiments were based on "Design of Experiments" to conduct the parametric study on the hybrid cooling system.

\section{Experimental setup}

For Stage-2 experimental purposes, a symmetrical part of the battery module was considered, which consists of a set of two Li-Ion pouch cells connected in parallel to form a mini module as shown in Fig. 3c. Similar battery modules with three tubes, five tubes and seven tubes were tested to understand the effect of thermal conductivity of the cooling mass. It was assumed that the electro-thermal characteristics of the large module are represented in the mini module, which is capable of discharging $20 \mathrm{~A}$ at $3.7 \mathrm{~V}$ at a $1 \mathrm{C}$-rate of discharge. Under current experiments, the battery module was discharged at $180 \mathrm{~A}$ (9 C-Rate of discharge). Charge/ discharge cycles are highly dynamic under the application of BEV and PHEV. The feasibility of a protection circuit module with battery system has great influence on energy storage capacity and efficiency, and subsequently influence on the results of the BTMS system. Thus, all the battery modules under the test conditions were supplied with appropriate protection circuit module to avoid the uncertainty in voltage applied and current drawn during the charge discharge cycles.

For the parametric study, two Li-Ion cells were immersed in molten PCM with a gap of 5, 10 and $15 \mathrm{~mm}$ from each other. The gap between the cells represents the mass of the PCM. The minimum gap is $5 \mathrm{~mm}$, since the thickness of the copper tube is $4.76 \mathrm{~mm}$. The maximum thickness is $15 \mathrm{~mm}$, as found in previous works [42]. Mass of the PCM used in each case is calculated by taking the effective volume between the battery cells and multiplying by the density of the PCM. The melting temperature of the PCM decides the desired operating temperature of the cooling system. Therefore, care needs to be taken while selecting a suitable PCM for the given application [5]. However, paraffin-based PCMs and their composites exhibited thermal stability for repeated solidification and melting $[43,44]$. In the current research work, the temperature 

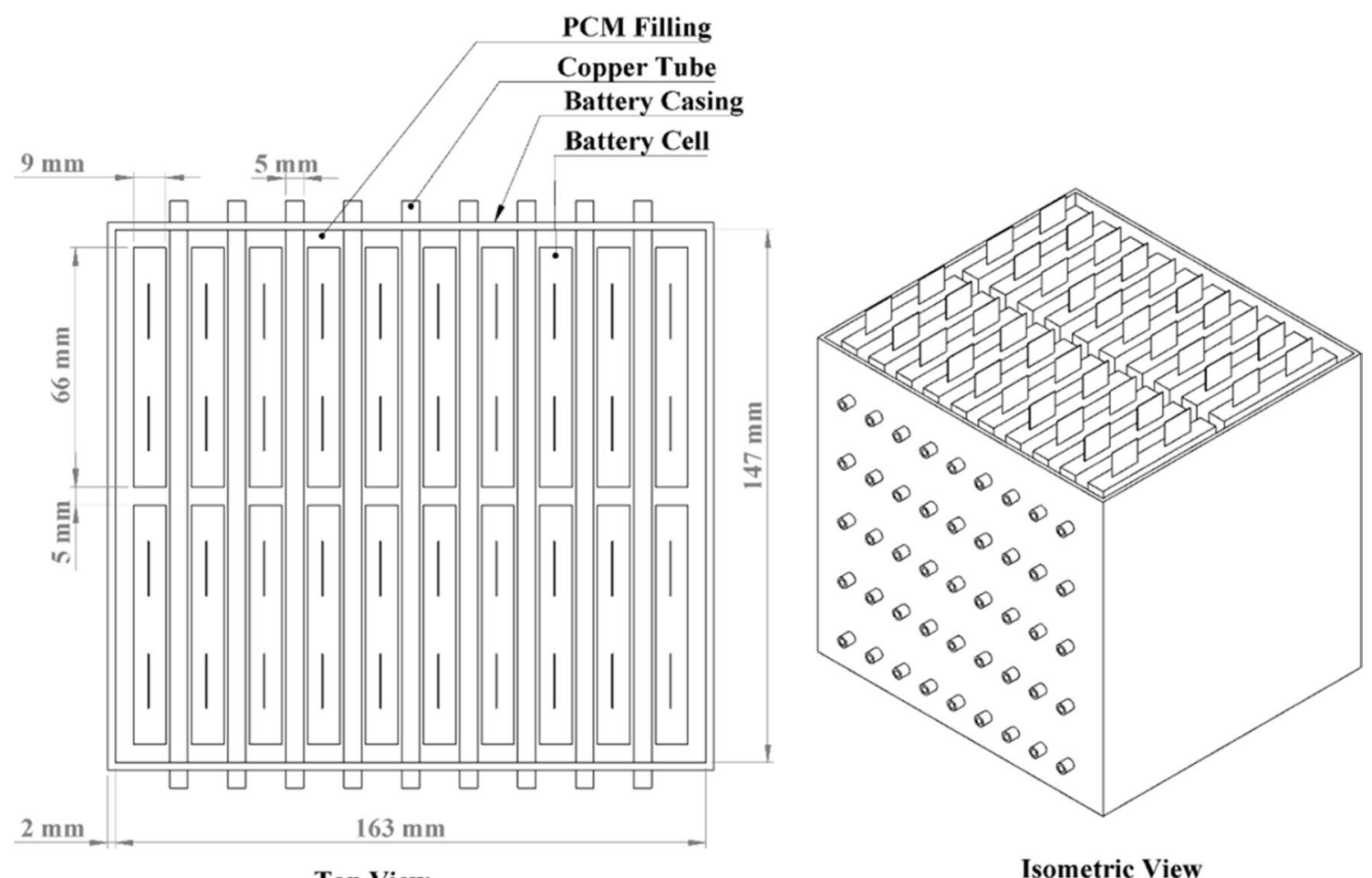

Top View

Isometric View

Fig. 1 The proposed design of the Li-Ion battery module with $20 \mathrm{Li}-\mathrm{Ion}$ cells

of the battery needs to be maintained within $50{ }^{\circ} \mathrm{C}$. Paraffin C20-C33 was chosen as the best PCM for cooling [45]. All the thermo-physical properties of the paraffin-based PCM are listed in Table 4.

Capillary copper tubes of 3/16 inch (OD: $4.8 \mathrm{~mm}$ and thickness: $0.8 \mathrm{~mm}$, as per ASTM B280 standards) were inserted through the PCM between the Li-Ion cells as shown in Fig. 3c. The number of copper tubes was varied to influence the thermal conductivity of the cooling mass. The thermal conductivity for paraffin is $0.2 \mathrm{~W} / \mathrm{m} \mathrm{K}$ and for copper $386 \mathrm{~W} / \mathrm{m} \mathrm{K}$. Effective thermal conductivity of PCC cooling mass was calculated using Eqs. (1) and (2) and by referring to previous works [26]. Copper tubes were placed at equidistance and the number of tubes was chosen as 3,5 and 7, so as to provide a sufficient gap to fill the paraffin. Effective thermal conductivity for 3, 5 and 7 tubes was 15.4, 24.1 and $34.2 \mathrm{~W} / \mathrm{m} \mathrm{K}$, respectively. By inserting seven copper tubes, the thermal conductivity of PCM increased 171 times of its pure value. In case of $\mathrm{Li}$ et al., it can be noticed that the effective thermal conductivity of PCM-metal composite was 218 times of the pure value of PCM [29].

$K_{\text {eff }}=(1-\varepsilon) K_{\text {pcm }}+\varepsilon K_{\text {metal }}$,

Porosity, $\varepsilon=\frac{\text { pore volume }}{\text { total volume }}$, where $K_{\text {eff }}$ is the effective thermal conductivity and $\varepsilon$ is the permeability of the PCM. $K_{\text {pcm }}$ and $K_{\text {metal }}$ present the thermal conductivity of PCM and metal, respectively.

For a hybrid cooling mechanism, water is chosen as the coolant that can circulate through the PCM cooling mass by using capillary copper tubes. To keep the circulation of water from the reservoir, through the capillary copper tubes and then back to the reservoir, a pump with a maximum discharge capacity of $27 \mathrm{~L} / \mathrm{min}$ was used. The pump operated at $100 \mathrm{~V}$ with a power rating of $40 \mathrm{~W}$ at $50 \mathrm{~Hz}$. Precautions were taken not to dry up the pump while it was running to avoid physical damage. The WFL considered in the present work was within the range of $1-2 \mathrm{~L} / \mathrm{min}$ by referring to a previous study [20]. The experimental setup and the major components are illustrated in Fig. 4.

\section{Temperature data acquisition}

Surface temperature measurement was crucial for the current work. A K-type thermocouple made by OMEGA Engineering was used to sense the temperature. Specifications of the SA1XL-K-SRTC thermocouple are listed in Table 5. A National Instruments data logger 'NI 9213' was used to record the temperature. NI 9213 comes with 16 thermocouple channels with 1 internal auto zero channel and 1 coldjunction compensation channel. It has the analog to digital conversion (ADC) resolution of 24 bits with a voltage 
Fig. 2 Experimentation flowchart

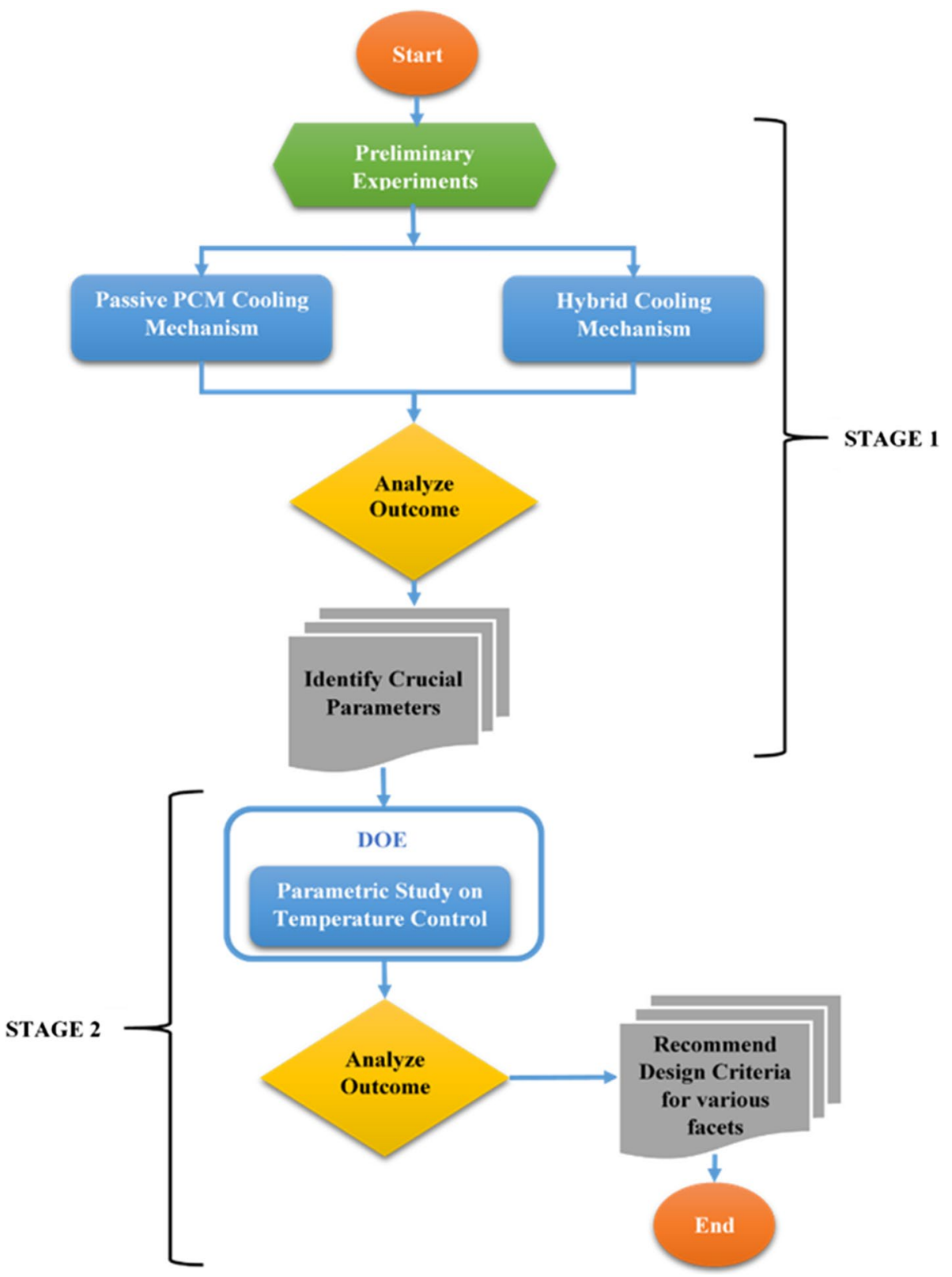

measurement range of $\pm 78.125 \mathrm{mV}$. It works with most of the National Institute of Standards and Technology (NIST)compliant thermocouples types. It operates with two modes of measurements, high resolution and high speed. The sensitivity of the data logger for various thermocouple types is shown in Table 6.

\section{Electronic DC load}

To test the battery for its discharge temperature, a programmable electronic load manufactured by ITECH Electronics with the model name 'IT8514C+' was used to discharge the battery at various C-rates. The electronic load comes with 'IT9320' software, which is capable of programming various discharge modes such as constant current (CC), constant voltage $(\mathrm{CV})$, constant resistance $(\mathrm{CR})$ and constant wattage (CW). The rated input values for 'IT8514C+' are shown in Table 7.

\section{Design of experiments}

DOE is an effective method of planning, conducting and analyzing experiments to draw valid and meaningful conclusions. The most important advantage of statistical DOE in comparison with classical engineering approach is that several design or process variables can be simultaneously studied for a complete insight into the combined effects of 
(a)

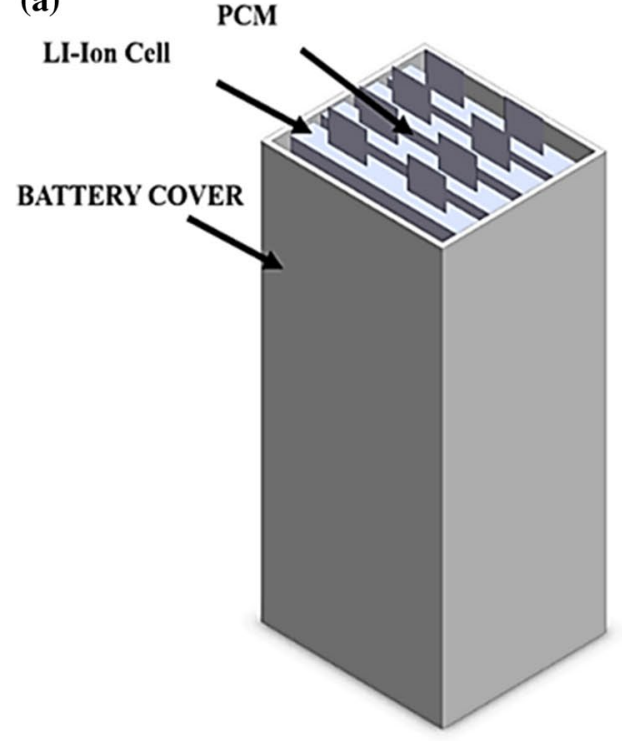

(b)

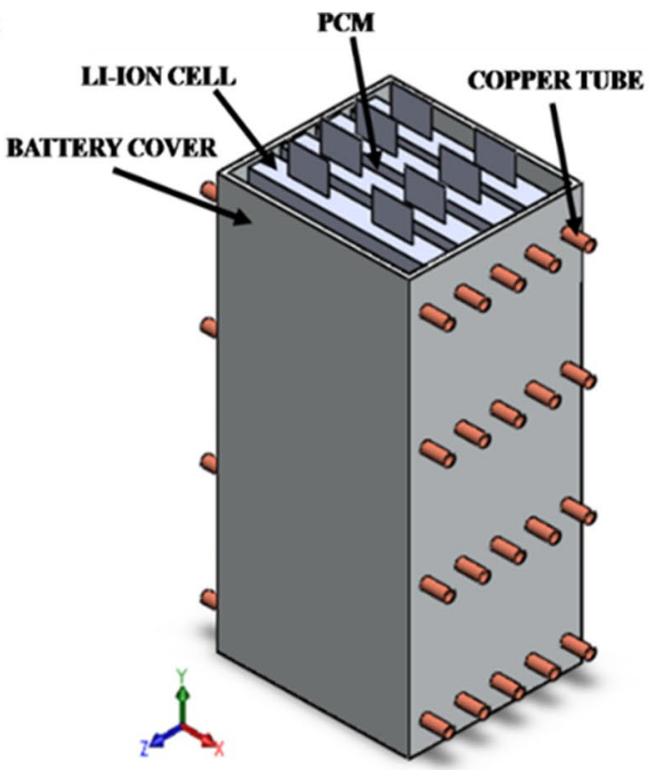

(c)

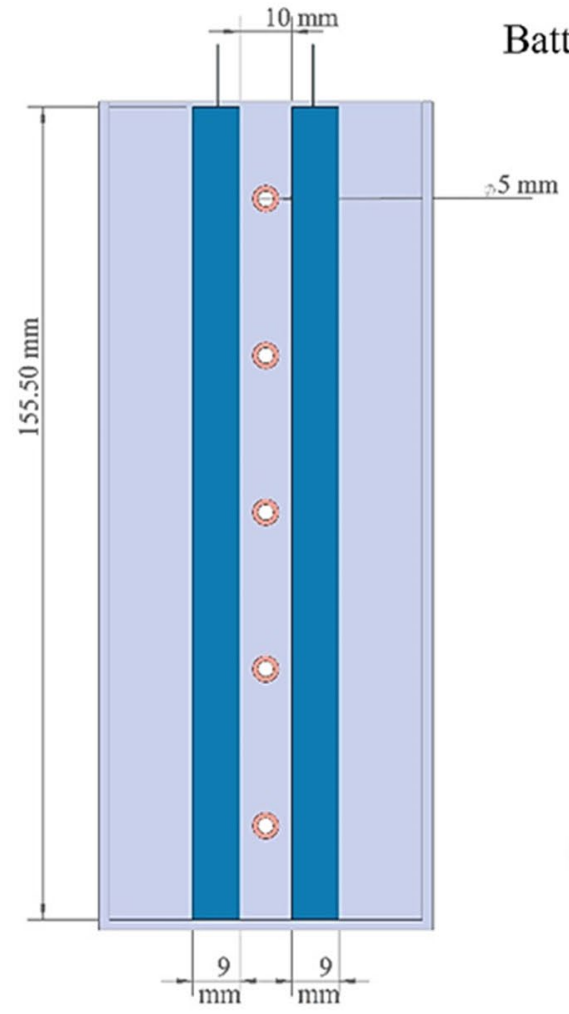

Front View

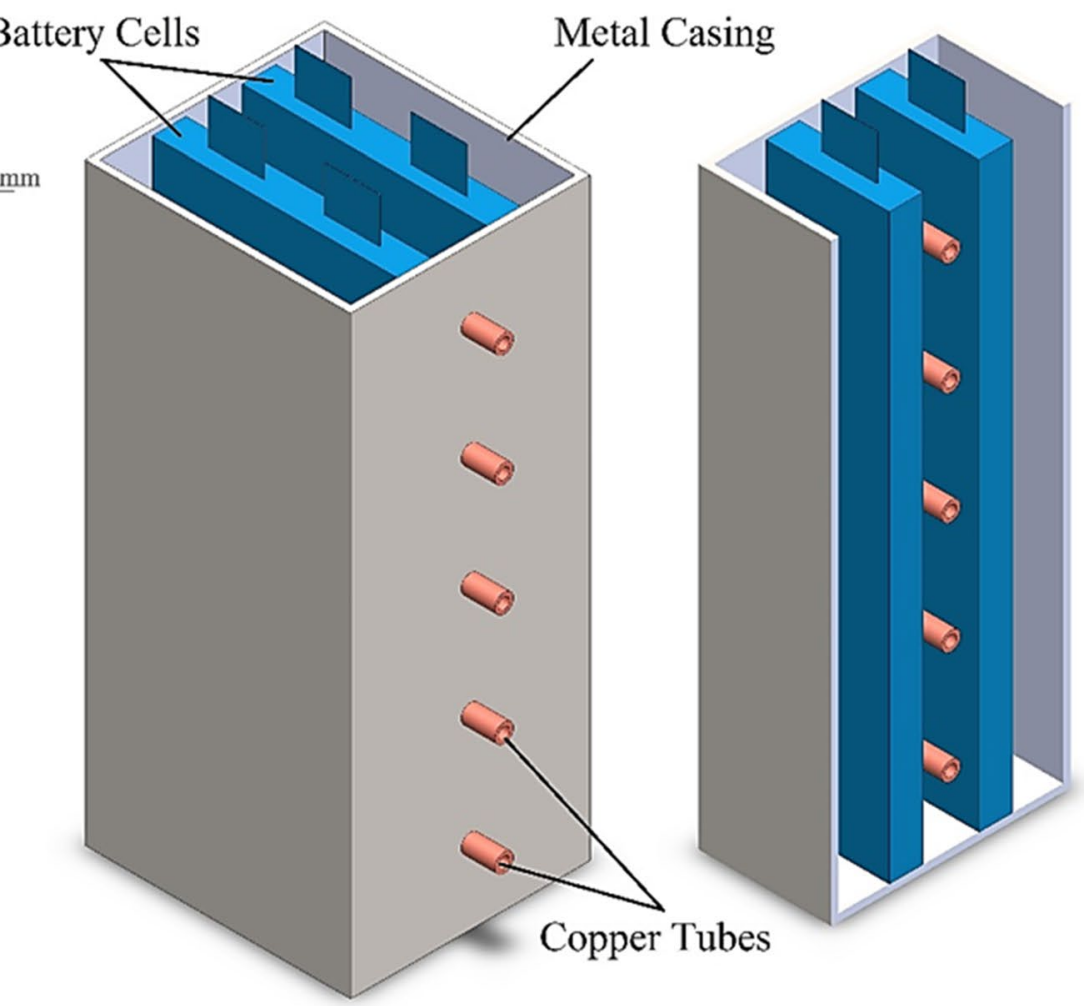

Isometruc View
Sectional View

Fig. 3 Battery modules for a pure PCM cooling and b hybrid cooling, $\mathbf{c}$ mini-module for Stage-2 experiments

input variables on the response measured under experimental investigation [46]. More specifically, in many cases, the number of experimental runs could be reduced, the optimal process variables can be determined, experimental error can be determined through a developed model equation, and the effects and significance of design or process variables on the performance characteristics can be determined. Response surface modeling (RSM) is a combination of mathematical and statistical techniques that is useful for the modeling and analysis of problems, in which a response of interest is influenced by several variables and the objective is to optimize the response [46]. Furthermore, the importance and 
Table 4 Properties of paraffin-based PCM material [45]

\begin{tabular}{ll}
\hline Paraffin C20-C33 & Typical values \\
\hline Melting range & $48-50{ }^{\circ} \mathrm{C}$ \\
Specific heat & $2.384 \mathrm{~kJ} /(\mathrm{kg} \mathrm{K})$ \\
Density of solid at $20^{\circ} \mathrm{C}$ & $0.912 \mathrm{~kg} / \mathrm{L}$ \\
Density of liquid at $70^{\circ} \mathrm{C}$ & $0.769 \mathrm{~kg} / \mathrm{L}$ \\
Thermal conductivity & $0.21 \mathrm{~W} /(\mathrm{m} \mathrm{K})$ \\
\hline
\end{tabular}

use of DOE and RSM techniques under various science and technologies are reviewed by Granato et al. [47].

Through the literature review, it is understood that an active air cooling is not efficient in controlling the temperature and maintaining the uniform distribution of heat within a large battery pack used under high discharge rates. A pure PCM-based cooling is good in controlling the temperature and uniform distribution of heat; however, at higher C-rates and repeated charge/discharge cycles, its temperature uniformity reaches an almost critical value due to the complete

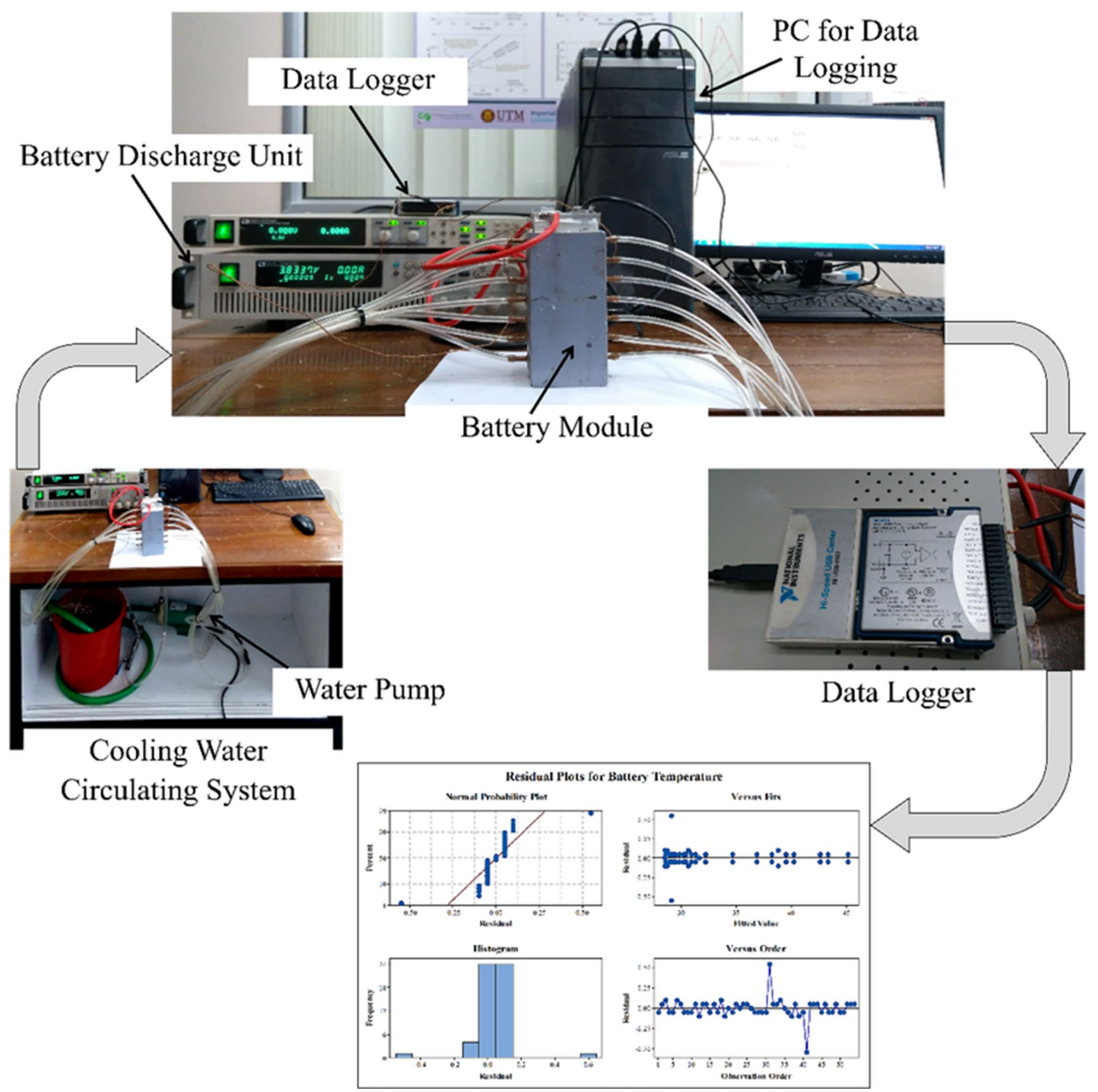

Fig. 4 Experimental setup with major components 
Table 5 Specifications of thermocouple used for temperature sensing

\begin{tabular}{ll}
\hline Properties & Value \\
\hline Make & OMEGA \\
Model & SA1XL-K-SRTC \\
Type & K-Type \\
Positive leg & Chromel (90\% Ni and 10\%Cr) \\
Negative leg & Alumel $(95 \% \mathrm{Ni}, 2 \% \mathrm{Mg}, 2 \%$ \\
& $\mathrm{Al}$ and $1 \% \mathrm{Si})$ \\
Rated temperature (self-adhesive) & $260{ }^{\circ} \mathrm{C}$ \\
Rated temperature (paste on) & $315^{\circ} \mathrm{C}$ \\
Patch length & $1.0^{\prime \prime}(25 \mathrm{~mm})$ \\
Patch width & $0.375^{\prime \prime}(9.5 \mathrm{~mm})$ \\
Strip length & $1.0^{\prime \prime}(25 \mathrm{~mm})$ \\
Strip width & $0.5^{\prime \prime}(12.7 \mathrm{~mm})$ \\
Strip thickness & $0.001^{\prime \prime}$ \\
Response time & $<0.15 \mathrm{~s}$ \\
Lead wire & 30 AWG fiberglass \\
\hline
\end{tabular}

Table 6 Data logger temperature measurement sensitivity

\begin{tabular}{ll}
\hline High-resolution mode $\left({ }^{\circ} \mathrm{C}\right)$ & \\
Types J, K, T, E, N & $<0.02$ \\
Types B, R, S & $<0.15$ \\
High-speed mode $\left({ }^{\circ} \mathrm{C}\right)$ & \\
Types J, K, T, E & $<0.25$ \\
Type N & $<0.35$ \\
Type B & $<1.2$ \\
Types R, S & $<2.8$ \\
\hline
\end{tabular}

Table 7 Rated input values for IT8514C + DC load

\begin{tabular}{lll}
\hline Properties & Values & \\
\hline Input voltage & $0-120 \mathrm{~V}$ & $0-240 \mathrm{~A}$ \\
Input current & $0-24 \mathrm{~A}$ & \\
Input power & $1500 \mathrm{~W}$ & $2.5 \mathrm{~V} @ 240 \mathrm{~A}$ \\
$\begin{array}{l}\text { Minimum operating } \\
\text { voltage }\end{array}$ & $0.25 \mathrm{~V} \mathrm{@} \mathrm{24A}$ & \\
\hline
\end{tabular}

melting of PCM. In case of hybrid cooling propped by Hemery et al. and Ling et al., the stream of air flow assisted in carrying away the latent heat out of the PCM cooling mass $[48,49]$. Similar results are evident while conducting preliminary experiments under Stage-1. Figure 5 illustrates the maximum temperature and temperature difference by comparing pure PCM and hybrid cooling methods. For temperature control, pure PCM cooling seems to be better at higher discharge rates. However, temperature uniformity is better under hybrid cooling. Thus, the present work extended to Stage-2 consists of developing regression models for hybrid battery thermal management by using DOE along with RSM, based on full factorial design. The influence and interaction of each design parameter, chosen on the desired output responses based on the preliminary experiments, have been studied with the help of various plots.

A full factorial DOE was designed and the number of experimental runs was computed by taking three factors and three levels. Since there were two thermocouples attached to individual Li-Ion cells, the temperature reading was considered as two replications. The number of experiments, $N=n$ $\times L^{F}=54$, where $n=$ number of replications; $L=$ number of levels and $F=$ number of factors (Table 8 ). The number of variant groups compared, $m=L^{F}=27$. For each of the experimental runs, the WFL and the maximum temperature of the Li-Ion battery were recorded. For maintaining identical conditions for two replications, two sets of batteries were packed with the cooling mass and the PCC in the container. The battery with standard specifications was used to facilitate the comparison of the results with previous research studies.

The hybrid cooling system design parameters, such as mass of PCM, thermal conductivity of the PCC, WFL, type of coolant, and type of PCM, have a high influence on the battery temperature and temperature uniformity. The design parameters and their corresponding levels considered for experimentation and linear regression modeling are shown in Table 8.

The correlated values for high, medium and low levels of all the input parameters were considered on the basis of the expected output response. The values of the input parameters used for the linear regression model are tabulated in Table 9. For regression equation and for plots and graphs, the thermal conductivity values obtained by Eq. (1) are divided by the scaling factor of 3.35. Investigating the influence of all input parameters and their interactions on the output parameter was the prime objective of the experimentation.

\section{Results and discussions}

In statistical analysis, the significance of influence for all selected factors and their interactions on output response are identified first, followed by the explanation of the effect of interaction between the parameters and the desired output responses by using surface response curves and contour graphs. ANOVA assists in determining these parameters.

\section{ANOVA}

The temperature of the battery (Temp) was analyzed for the influence of control parameters by applying DOE tool MiniTab ${ }^{\circledR}$ Version 17. The ANOVA provides the results as shown in Table 10. The terms used in the ANOVA table are 

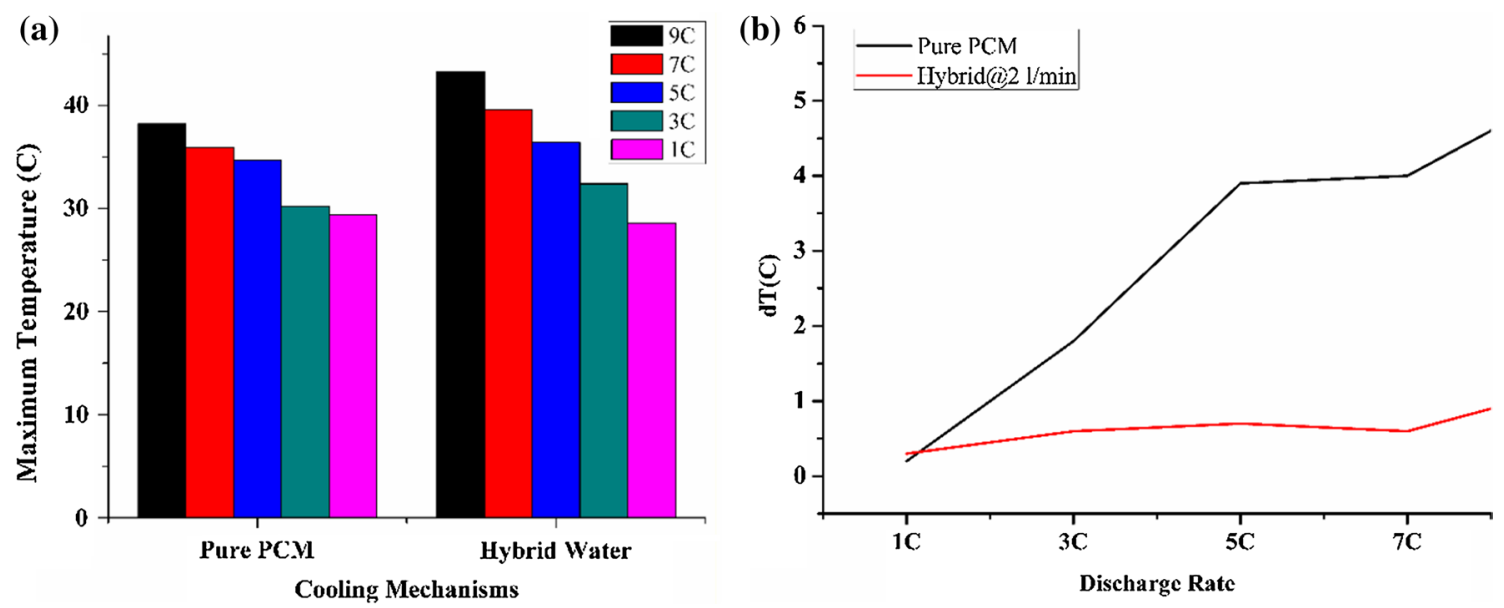

Fig. 5 Temperature profiles of pure PCM and hybrid cooling: a maximum temperature and $\mathbf{b}$ temperature difference at various C-rates

Table 8 Input and output parameters of the current study

\begin{tabular}{lll}
\hline Input parameters & Levels & Output parameters \\
\hline Mass of PCM & 3 & Battery temperature \\
Thermal conductivity of PCC & 3 & \\
Rate of water flow (WFL) & 3 & \\
\hline
\end{tabular}

Table 9 The design factors and their levels

\begin{tabular}{llllc}
\hline Short name & Name of factor & Low & Medium & High \\
\hline PCM & Mass of PCM & 0.05 & 0.1 & 0.15 \\
PCC & Thermal conductivity & 4.6 & 7.2 & 10.2 \\
WFL & Rate of water flow & 1 & 1.5 & 2 \\
\hline
\end{tabular}

explained as follows. Under the listed source terms, which are the sources of variation in data, the first three terms are the design factors considered in the present work and their direct impact on the response term; they are referred to as main effect. The subsequent three terms are the interaction of any two design factors and their impact on the response term; they are known as interaction effect. The seventh term is three-dimensional interaction, where interaction of all the three factors and its influence on the output response are considered. The eighth term is the errors or residuals. Under ANOVA, the error is known as the assumption of homogeneity of variances and normally distributed about the sample means.

Degrees of freedom (DoF) represent the number of terms contributed toward prediction error. For main effect, the DoF is considered as one less than the number of levels $(L-1)$. Similarly, DoF from interaction effect is the multiplication of DoF of the terms interacting with each other. DoF of error is estimated as the difference between the total number of experimental trials and the number of variant groups compared $($ Error $=N-m)$. Sequential sum of squares (Seq_SS) represents the variation of different terms of the model. Adjusted sum of squares (Adj_SS) is the obtained sum of squares after excluding non-contributory (insignificant) terms from the model. Mean square (MS) is determined according to the ratio of corresponding values of the sum
Table 10 ANOVA of temperature of Li-Ion battery

\begin{tabular}{lcccccc}
\hline Source & DoF & Seq_SS & Adj_SS & Adj_MS & $F$ value & $P$ value \\
\hline PCM & 2 & 1013.18 & 1013.18 & 506.59 & 17424.1200 & 0.0000 \\
PCC & 2 & 74.469 & 74.469 & 37.235 & 1280.6800 & 0.0000 \\
WFL & 2 & 78.787 & 78.787 & 39.394 & 1354.9400 & 0.0000 \\
PCM $\times$ PCC & 4 & 170.581 & 170.581 & 42.645 & 1466.7800 & 0.0000 \\
PCM $\times$ WFL & 4 & 72.04 & 72.04 & 18.01 & 619.4500 & 0.0000 \\
PCC $\times$ WFL & 4 & 35.944 & 35.944 & 8.986 & 309.0700 & 0.0000 \\
PCM $\times$ PCC $\times$ WFL & 8 & 18.906 & 18.906 & 2.363 & 81.2800 & 0.0000 \\
Error & 27 & 0.785 & 0.785 & 0.029 & & \\
Total & 53 & 1464.692 & & & & \\
\hline
\end{tabular}

$S=0.170511, R-\mathrm{Sq}=99.95 \%$ 
of squares and DoF. Adjusted mean square (Adj_MS) is the MS obtained after excluding non-contributing terms in the response equation. The $F$ value is determined according to the ratio of adjusted MS and residual error, and is used in regression to test the hypothesis. $P$ value is the probability that measures evidences against the null hypothesis and $R$-square $(R-\mathrm{Sq})$ is the measure of how close the data are with the fitted regression line. The data collected during experiments have shown reliability and accuracy that were perceived by the higher $R^{2}$ value $(99.95 \%)$ obtained from the analysis. From the ANOVA table, $P$ value for all the factors and their interactions scored more than the critical value $(\alpha=0.05)$, representing a 5\% risk and concluding that a potential difference exists.

\section{The regression model}

To test the relationship between the input variables of research interest, a regression model was developed as shown in Eq. (3). The output response of the equation depends on the values given for input parameters. PCM, PCC and WFL are the input parameters in the regression equation, as represented in Tables 8 and 9. Equation (3) comprises the individual and interaction effect of all three parameters on the output response. It can be observed that the regression model supports the results obtained by the ANOVA and provides an empirical relationship between the variables of study.

$$
\begin{aligned}
\text { Temp }= & 57.8-157 \mathrm{PCM}-0.09 \mathrm{PCC}-17.5 \mathrm{WFL} \\
& -5.4 \mathrm{PCM} \times \mathrm{PCC}+1.08 \mathrm{PCC} \times \mathrm{WFL} \\
& +90.4 \mathrm{WFL} \times \mathrm{PCM}-3.19 \mathrm{PCM} \times \mathrm{PCC} \times \mathrm{WFL} .
\end{aligned}
$$

The residual plot shown in Fig. 6 illustrates that all data points pertaining to battery temperature lie close to the best-fit line (mean line) on the normal plot. This signifies the reliability and normality of the data by neglecting minor deviances. It is noticed that the errors are normally distributed, which is substantiated by the residuals falling in a straight line. In addition, the fits and order plots did not reveal evidence of any pattern or unusual structure present in the data. The reliability of regression analysis and validation of the regression model are verified through the linearity, normality and residue, presented in the residual plots.

The main effect plot shown in Fig. 7 represents the effect of all three parameters as highly significant on the battery

\section{Residual Plots for Battery Temperature}
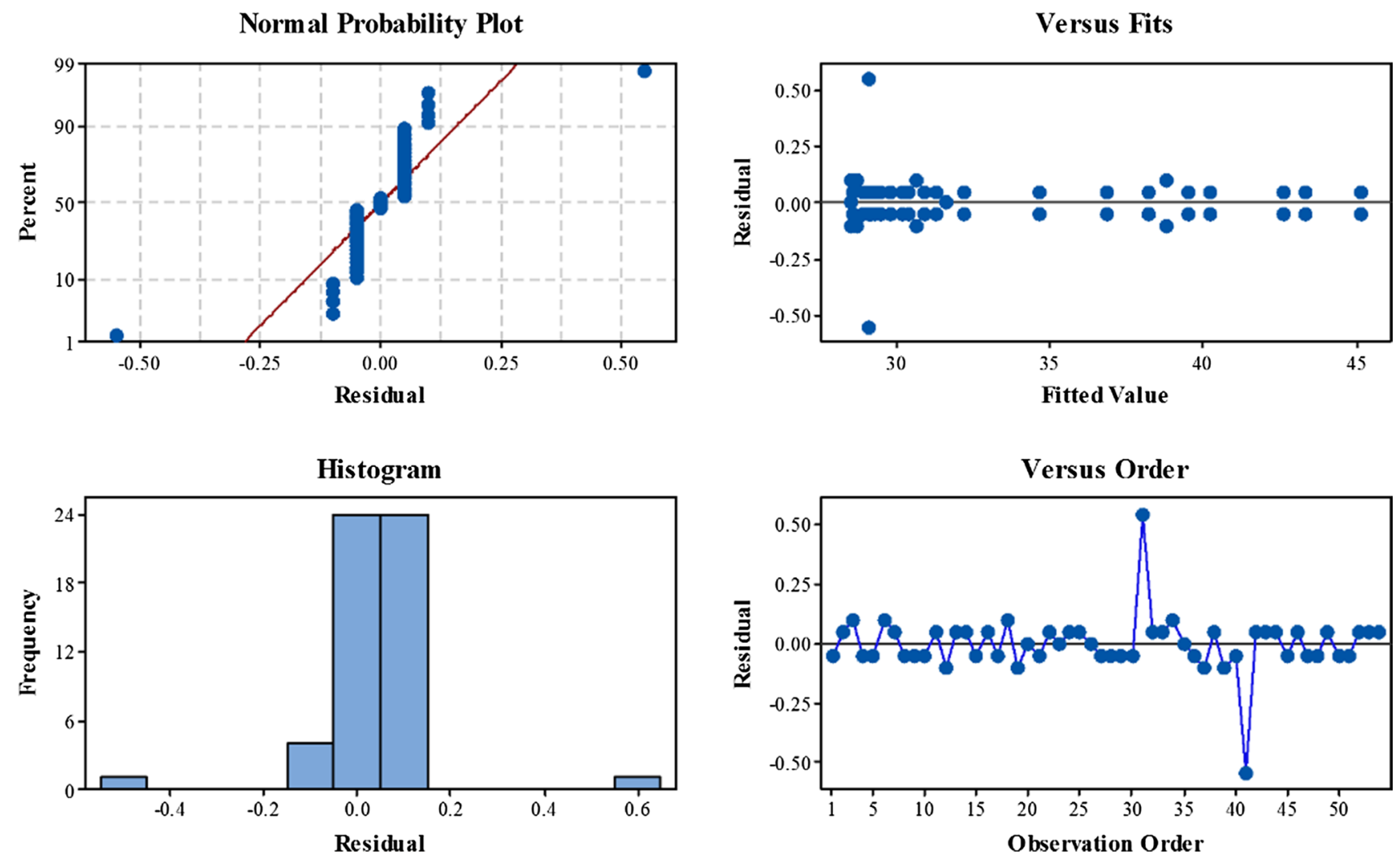

Fig. 6 Residual plots for battery temperature 
temperature, which seems to be a logical understanding. However, the slopes of the mass of PCM and WFL are inclined downward and indicate that if the values are higher, then the temperature is lower. On the other hand, thermal conductivity of the upward inclining PCC slope representing higher values can cause a rise in temperature. This is true in the sense that an increase of copper tubes to raise the thermal conductivity causes a low-volume ratio of paraffin. Thermal diffusion from the battery to paraffin occurs at a lower temperature causing a rise in the battery temperature. However, a balance between the selected design parameters has to be maintained for a desired thermal management of the battery pack, which is attained by using surface, contour and optimization plots, thereby increasing the performance and life of the Li-Ion cells.

\section{Contour and surface plots}

The interaction of any two design parameters on the battery pack temperature, keeping the third parameter at an average value (middle level), is illustrated in contour plots. The parameters considered in the present work are mass of PCM (which directly influences the heat capacity of paraffin), thermal conductivity of PCC (which depends on the number of copper tubes inserted between two battery cells), and WFL. The heat capacity of paraffin promotes the heat diffusion from the battery surface, whereas the other two parameters assist in heat dissipation from PCM to the atmosphere. It can be noticed from the contour plot in Fig. 8a that low temperature can be achieved by keeping the mass of paraffin as high as possible and by keeping the number of tubes to as low as three. However, the best agreement can be seen with both parameters being at medium levels. The temperature contour of PCC versus WFL is shown in Fig. 8b, which illustrates a high WFL is required to control the temperature when the number of copper tubes is low. However, a higher WFL is not desirable since it requires high pumping power and maintenance of high pressure lines for water circulation. It can be seen from the curve that better cooling is achieved by keeping both parameters at medium levels. Figure $8 \mathrm{c}$ illustrates the relation between the heat capacity of PCM and WFL. It shows that for a higher heat capacity of PCM, a substantial reduction in water cooling can be achieved. In other terms, the pumping effort could be reduced to a large extent. The heat capacity can be increased either by selecting the best paraffin or by increasing the mass of PCM. Increasing the mass of paraffin is an easy solution. However, it could increase the size and bulkiness of the battery pack. It is obvious that the paraffin-based PCM materials are characterized by low thermal conductivity and eventually fail to dissipate the heat away from the cooling mass. Introducing the water flow channel through the

\section{Main Effects Plot for Temperature}

Data Means

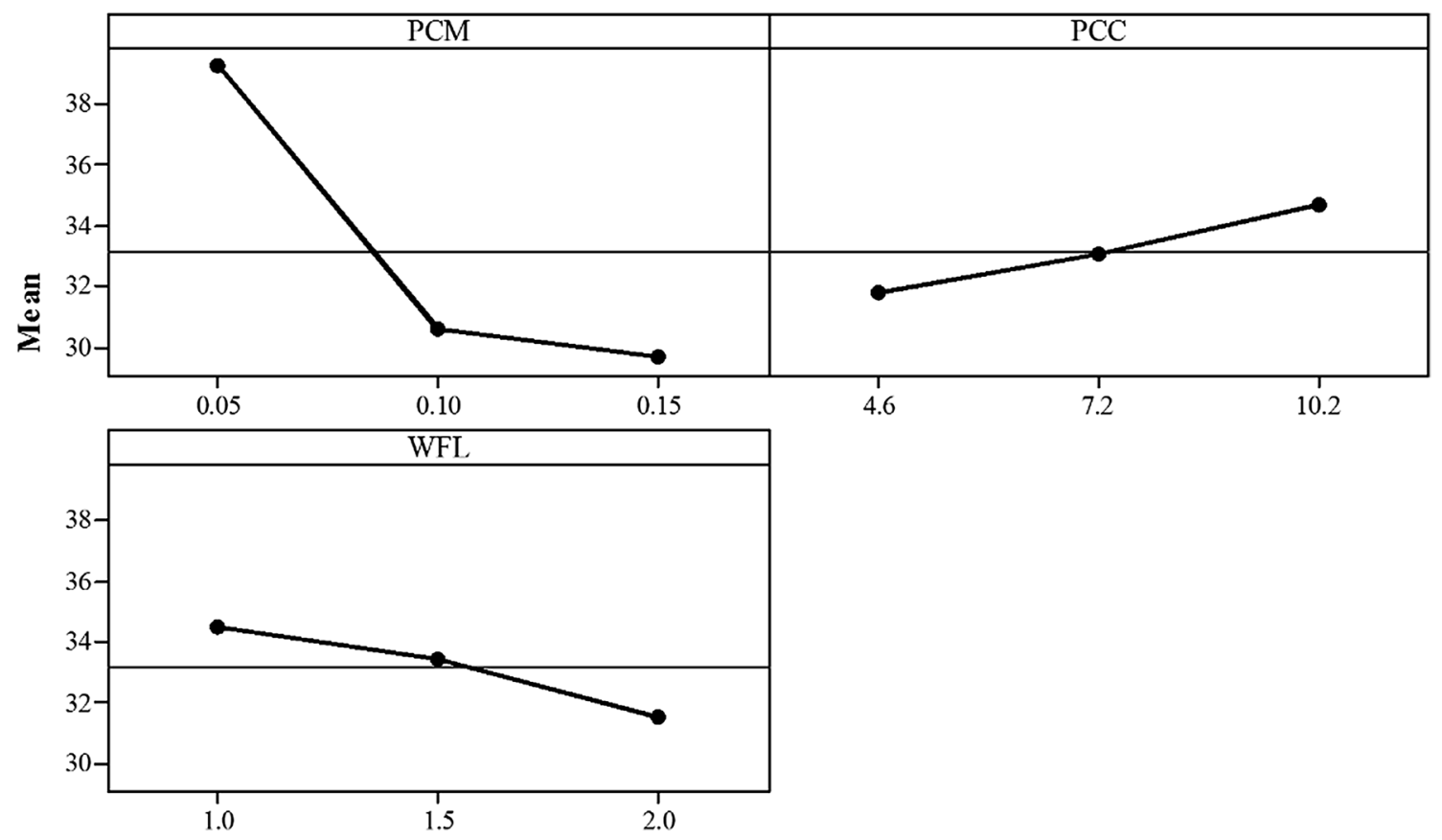

Fig. 7 Main effect plots of PCM, PCC and WFL 
Fig. 8 Temperature contour plots: a PCM v/s PCC, b PCC v/s WFL and $\mathbf{c}$ PCM v/s WFL

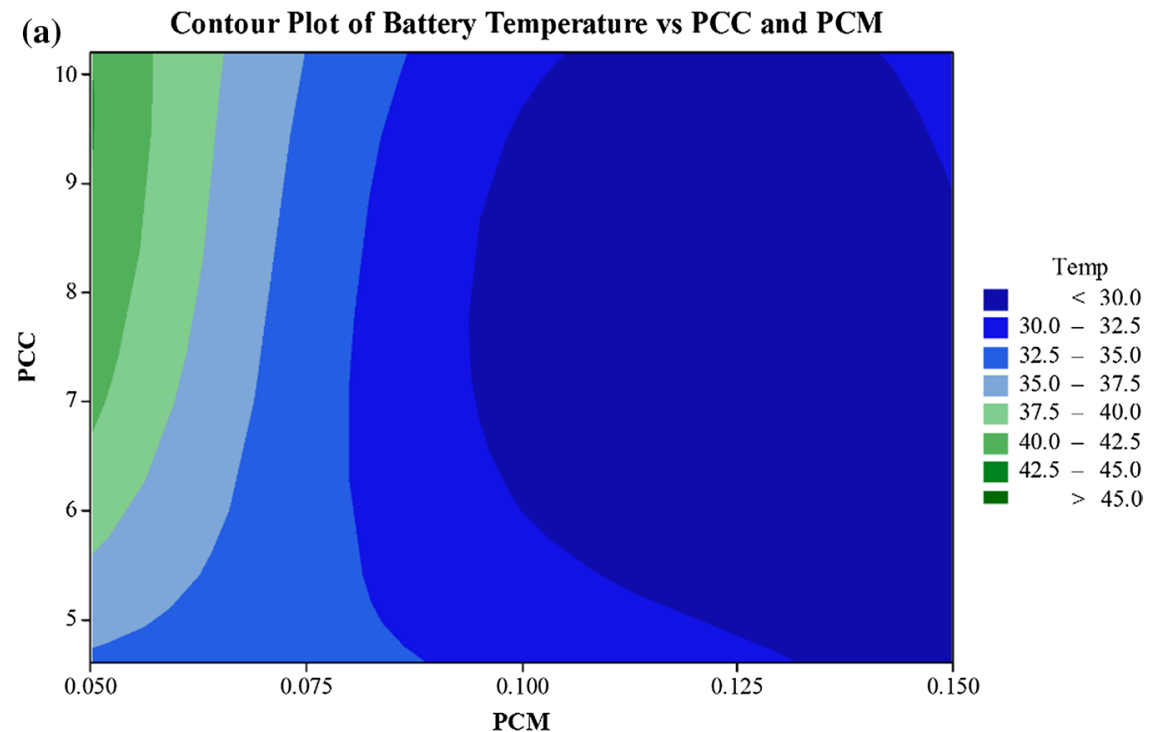

(b) Contour Plot of Battery Temperature vs PCC and WFL

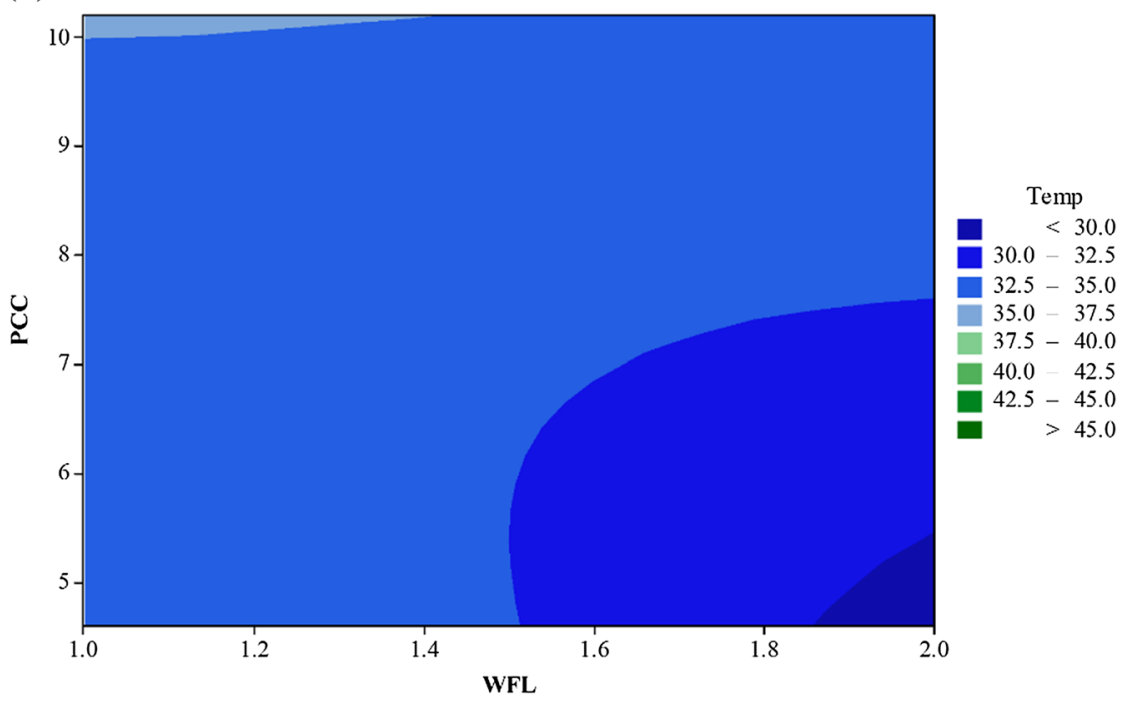

(c) Contour Plot of Battery Temperature vs PCM and WFL

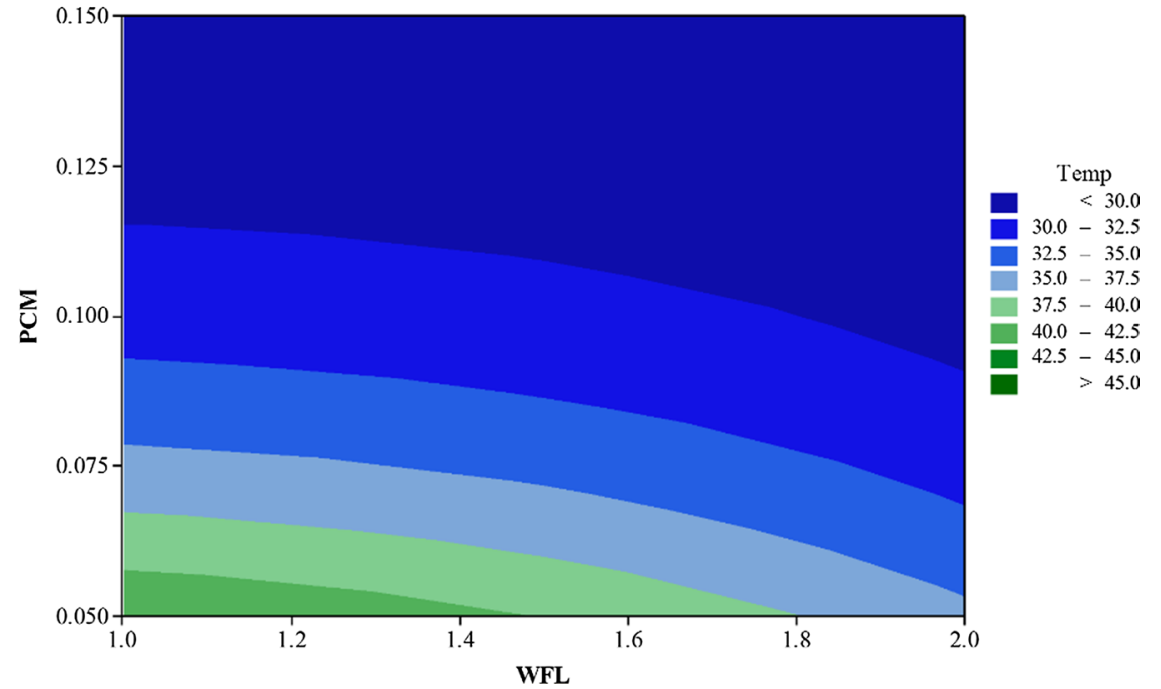


paraffin mass could provide a balanced temperature control for a given battery pack.

Surface plots are another tool to understand the interaction effect of all three parameters over the desired response output. Figure 8 clearly illustrates the combined effect of all three design parameters on the temperature of the battery pack. Figure 9a illustrates that an increase in the heat capacity of PCM has a high influence until a certain limit; however, the mass of paraffin is increased for higher values of heat capacity. By increasing the mass of paraffin beyond a certain limit, the temperature curve seems to be horizontal, expressing no further significant effect on temperature control. This phenomenon is in agreement with the results obtained by Javani et al. [42]. In the curve, the effect of thermal conductivity has shown very low significance on the temperature control. It means that increasing the number of copper tubes does not really influence the temperature control of the battery pack. Figure $9 \mathrm{~b}$ represents battery temperature in terms of WFL and the number of copper tubes. WFL has a significant effect in controlling the temperature when the flow rate is increased, whereas an increase in the number of copper tubes has an inverse effect on temperature control, and it can be noticed that the copper tubes providing thermal conductivity are also used as a channel for water flow. Thus, a minimum number of copper tubes are an essential part of a hybrid cooling pack presented in this work. The interaction effect of heat capacity of PCM and WFL on battery temperature is shown in Fig. 9c. The effect is similar to that of Fig. 9a and illustrates that the heat capacity of paraffin has a higher significant effect on the battery temperature than the WFL. It should be noted that the use of copper tubes and circulating water is to carry the heat away from the PCM to avoid the heat lock during continuous charge/discharge cycles of the battery with higher discharge rates.

\section{Optimization using regression equation}

The temperature response values for various combinations of design input parameters are tabulated in Table 11 by applying the regression equation (Eq. 3) developed by the statistical model. These values represent the interaction effect of design parameters and assists in deciding the appropriate value for each parameter on the desired output response. Referring to the various combinations for temperature response (Temp) under Table 11, it can be noticed that two combinations of input parameters are possible to attain the temperature control of $\sim 40{ }^{\circ} \mathrm{C}$ and $\sim 30{ }^{\circ} \mathrm{C}$. It illustrates that for any desired temperature control, the input parameters have to be chosen with care to make a system with light weight, low operating cost and less expensive. Increasing PCC would require an increase in the amount of copper in the PCM-metal matrix, which
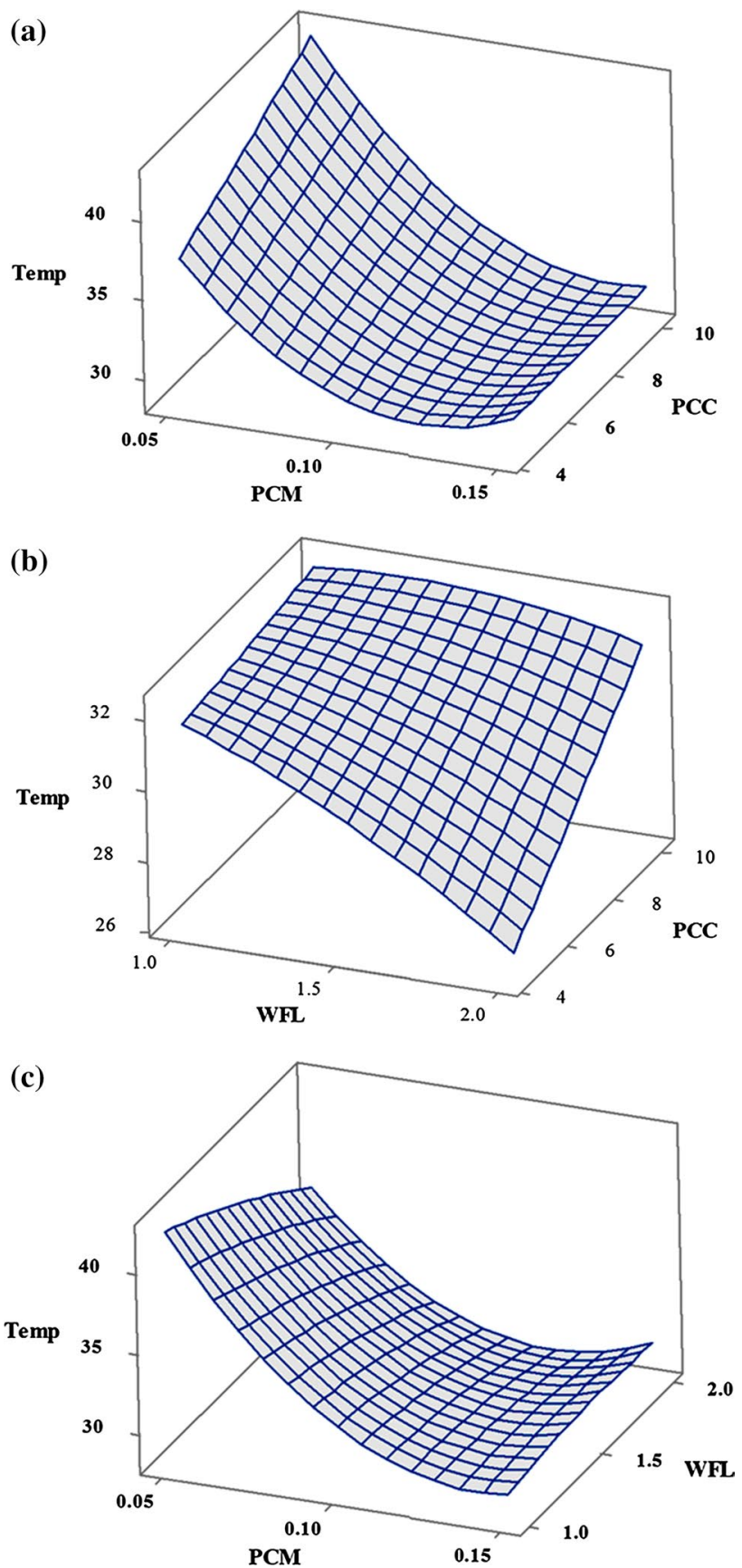

Fig. 9 Surface plot of battery temperature: a PCM v/s PCC, b PCC v/s WFL and c PCM v/s WFL

Table 11 Optimization values for various combinations of PCM, PCC and WFL

\begin{tabular}{lllll}
\hline Combination & PCM $(\mathrm{kg})$ & PCC $(\mathrm{W} / \mathrm{m} \mathrm{K})$ & WFL $(\mathrm{L} / \mathrm{min})$ & $\mathrm{Temp}\left({ }^{\circ} \mathrm{C}\right)$ \\
\hline 1 & 0.05 & 10.8 & 2.0 & 39.98 \\
2 & 0.05 & 4.8 & 1.0 & 39.66 \\
3 & 0.1 & 4.8 & 2.0 & 29.46 \\
4 & 0.13 & 4.8 & 1.5 & 29.76 \\
5 & 0.15 & 4.8 & 2.0 & 27.82 \\
\hline
\end{tabular}


eventually increases the cost and weight of the thermal management system. Similarly, increasing PCM would increase the volume of the battery box, thereby increasing the size of the thermal management system, and increasing WFL would necessitate an increase in the pumping power required for the cooling system, which would be parasitic.

Considering the lowest and the highest values of all three design parameters of the present work, the highest temperature control $\left(27.82^{\circ} \mathrm{C}\right)$ is achieved as shown in Combination 5 of Table 11. The mass of PCM is at $0.15 \mathrm{~kg}$, the number of copper tubes is at 3 with the corresponding thermal conductivity value of $4.8 \mathrm{~W} / \mathrm{m} \mathrm{K}$ and $\mathrm{WFL}$ at $2 \mathrm{~L} / \mathrm{min}$. According to Xu et al., for a mini-channel of $9 \mathrm{~mm}^{2}$ cross section, the pumping power for $1 \mathrm{~L} / \mathrm{min}$ is $5 \times 10^{-3} \mathrm{~W} /$ cell. They also predicted that the increase in pressure drop would be 20 times with the increase in every liter of flow rate per minute. Subsequently, the increase in power would be 200 times with the increase in every liter of flow rate per minute [21]. In the present work, the cross section of copper tube is $8.04 \mathrm{~mm}^{2}$, which is similar to that of the mini-channels proposed by Xu et al. However, with the presence of PCM, the maximum flow rate required in the present work for discharge condition of 9C rate is 2 $\mathrm{L} / \mathrm{min}$, which would not be expensive in terms of pumping power. Thus, controlling the mass of copper and the mass of PCM plays a major role in designing the hybrid battery pack.

Increasing a single copper tube would increase the copper's volume by $653.25 \mathrm{~mm}^{3}$ and mass by approximately 6 $\mathrm{g} / \mathrm{cell}$. There are 20 cells in a module and the mass would be $120 \mathrm{~g} /$ module. The mass of a battery pack of an electric car would increase by $7.2 \mathrm{~kg}$. The mass of copper tube is considered only for PCC within the battery pack. Increase in tubing, required to carry the coolant from the pump to the battery pack, is not part of the calculation. Thus, it is advised to keep the lower amount of copper tubes for lightweight and low-cost battery packs.

Referring to Table 11, there are two combinations for the temperature control of $\sim 40{ }^{\circ} \mathrm{C}$. Combination 2 would be more optimal than Combination 1, since it proposes a lower number of copper tubes and a lower flow rate to achieve the same temperature control. This is possible since the heat capacity of the cooling system is increased due to the increase in volume of PCM, thereby sacrificing a part of heat dissipation. Similarly, to maintain the temperature of $\sim 30^{\circ} \mathrm{C}$, there are two combinations proposed in Table 11. Combination 3 is more optimal than Combination 4 as it proposes $30 \mathrm{~g}$ less PCM per cell, thereby reducing the mass of the battery pack of a fully electric car by $36 \mathrm{~kg}$. However, there is a slight increase in the flow rate that may require additional pumping power.

\section{Conclusions}

PCM-based cooling is attracting more attention in the present day due to its thermal stability on repeated solidification and melting. Hybrid cooling system is a new trend to overcome the thermal conductivity issue which is associated with pure PCM cooling. In the proposed hybrid cooling system for Li-Ion battery cells, paraffin-based PCM, copper tubes, aluminum casing and water are the major components of the system. Water is circulated through copper tubes and its interaction is only with the copper. Thus, corrosion and degrading or aging effect are not expected for copper tubes. Paraffin is most stable both in solid and liquid state and it is filled in the aluminum container that has contact with the outer surface of the copper tube. Any kind of reactions are not expected between paraffin and metals even at higher temperatures. Thus, the cooling system is expected to perform without aging issue or decay of performance. The proposed cooling system could perform effectively within the evaporation temperature of the paraffin material used in the system.

The present work has focused on three important design factors that affect the hybrid cooling system used for the temperature control of the Li-Ion battery pack. The temperature uniformity test concluded through preliminary experiments that hybrid cooling performs better than pure PCM cooling at higher discharge rates. This is in agreement with the work done by Hemery et al., who applied a liquid cooling plate with PCM to extract the latent heat of PCM [48]. Similarly, Ling et al. applied a stream of air to carry the latent heat stored in the PCM, which is in agreement with the present work [49].

A full factorial DOE technique was applied to conduct experiments and to analyze the influence of factors on the battery's temperature. A novel design for the hybrid cooling system was developed. Statistical regression model was used to discuss the optimization of the battery pack for a fully electric car. It can be concluded from the results that:

a. The mass of PCM is the major factor affecting the temperature control of the battery. It was ascertained that for a higher mass, the higher the heat capacity, the better is the control on temperature. However, beyond the critical value, there was no significant effect on the temperature control. This phenomenon is in agreement with the work by Javani et al. [27]. The optimum mass of PCM would provide a balance between temperature control and bulkiness of the cooling system.

b. Thermal conductivity of the PCC had a very low significance on the temperature control of the battery. However, copper tubes were inserted into the PCM to 
increase the thermal conductivity and to assist as a coolant flow channel. Thus, a minimum number of tubes are inevitable for hybrid cooling to carry the latent heat out of the PCM cooling mass.

c. WFL has shown a significant influence on the temperature control of batteries. Although its influence is low in comparison with the heat capacity of paraffin, water flow is essential to dissipate the latent heat of PCM during repeated charge/discharge cycles at higher discharge rates during which pure PCM cooling tends to fail [48, 49].

d. The hybrid cooling proposed in the present work has three design parameters, out of which the mass of PCM and the number of copper tubes would have a significant influence on the bulkiness and size of the battery pack. The application of the regression model, developed in the present work, has shown the optimal design criteria in reducing the overall mass of the battery pack.

e. The presence of PCM has made the requirement of coolant flow rate within $2 \mathrm{~L} / \mathrm{min}$. Thus, it has a very less significance in terms of pumping power. By changing the type of coolant or by increasing the flow rate above $2 \mathrm{~L} / \mathrm{m}$, better heat dissipation would make the battery pack more versatile in controlling the battery temperature. However, it would increase the pumping power and initial cost of the system.

f. The proposed battery pack with hybrid cooling is versatile to accommodate both liquid and air cooling. In case the module is used for scooters, hybrid cooling of the battery pack can be used with air stream (instead of liquid cooling) through the copper tubes.

\section{Limitation and scope for future work}

Hybrid cooling system for Li-Ion battery pack proposed in the current work represents only three design parameters. However, PCMs with different thermal properties, capillary tubes of metals with various thermal conductivities, and coolants with different cooling properties still need to be investigated, which could result in more compact and lighter battery packs. A similar battery pack can be investigated for hybrid PCM-air cooling by passing an air stream through the copper tubes. The battery pack considered in the present work was made of only two cells. A computational study followed by an experimental investigation for a complete battery module with 20 cells would be considered for future research work.

Open Access This article is distributed under the terms of the Creative Commons Attribution 4.0 International License (http://creativeco mmons.org/licenses/by/4.0/), which permits unrestricted use, distribution, and reproduction in any medium, provided you give appropriate credit to the original author(s) and the source, provide a link to the Creative Commons license, and indicate if changes were made.

\section{References}

1. Linder, M.: A portfolio of power-trains for Europe: a fact-based analysis. Fuel Cell, pp. 1-68, McKinsey \& Company (2010)

2. Braun, P.V., Cho, J., Pikul, J.H., King, W.P., Zhang, H.: High power rechargeable batteries. Curr. Opin. Solid State Mater. Sci. 16(4), 186-198 (2012)

3. Catenacci, M., Verdolini, E., Bosetti, V., Fiorese, G.: Going electric: expert survey on the future of battery technologies for electric vehicles. Energy Policy 61, 403-413 (2013)

4. Lundgren, C.A., Xu, K., Jow, T.R., Allen, J., Zhang, S.S.: Lithium-ion batteries and materials. In: Breitkopf, C., SwiderLyons, K. (eds.) Springer Handbook of Electrochemical Energy, pp. 449-495. Springer, Berlin (2017)

5. Ramadass, P., Haran, B., White, R., Popov, B.N.: Capacity fade of Sony 18650 cells cycled at elevated temperatures: Part II. Capacity fade analysis. J. Power Sources 112(2), 614-620 (2002)

6. Bandhauer, T.M., Garimella, S., Fuller, T.F.: A critical review of thermal issues in lithium-ion batteries. J. Electrochem. Soc. 158(3), R1 (2011)

7. George, A., Sulkes, M.: Performance of the Sony lithium-ion rechargeable battery, pp. 1-31. Army Research Laboratory (1993)

8. Chacko, S., Chung, Y.M.: Thermal modelling of Li-ion polymer battery for electric vehicle drive cycles. J. Power Sources 213, 296-303 (2012)

9. Fathabadi, H.: High thermal performance lithium-ion battery pack including hybrid active e passive thermal management system for using in hybrid/electric vehicles. Energy 70, 529-538 (2014)

10. Smith, K., Wang, C.: Power and thermal characterization of a lithium-ion battery pack for hybrid-electric vehicles. J. Power Sources 160, 662-673 (2006)

11. Wang, T., Tseng, K.J., Zhao, J., Wei, Z.: Thermal investigation of lithium-ion battery module with different cell arrangement structures and forced air-cooling strategies. Appl. Energy 134, 229-238 (2014)

12. Tong, W., Somasundaram, K., Birgersson, E., Mujumdar, A.S.: Thermo-electrochemical model for forced convection air cooling of a lithium-ion battery module. Appl. Therm. Eng. 99, 672-682 (2016)

13. Huat, L., Ye, Y., Tay, A.A.O., Tong, W., How, S., Chian, M.: Computational fluid dynamic and thermal analysis of Lithium-ion battery pack with air cooling. Appl. Energy 177, 783-792 (2016)

14. Tran, T., Harmand, S., Desmet, B., Filangi, S.: Experimental investigation on the feasibility of heat pipe cooling for HEV/EV lithium-ion battery. Appl. Therm. Eng. 63(2), 551-558 (2014)

15. Mohammadian, S.K., Rassoulinejad-Mousavi, S.M., Zhang, Y.: Thermal management improvement of an air-cooled high-power lithium-ion battery by embedding metal foam. J. Power Sources 296, 305-313 (2015)

16. Mohammadian, S.K., Zhang, Y.: Thermal management optimization of an air-cooled Li-ion battery module using pin-fin heat sinks for hybrid electric vehicles. J. Power Sources 273, 431-439 (2015)

17. Ye, Y., Saw, L.H., Shi, Y., Tay, A.A.O.: Numerical analyses on optimizing a heat pipe thermal management system for lithiumion batteries during fast charging. Appl. Therm. Eng. 86, 281-291 (2015)

18. Ye, Y., Shi, Y., Saw, L.H., Tay, A.A.O.: Performance assessment and optimization of a heat pipe thermal management system for fast charging lithium ion battery packs. Int. J. Heat Mass Transf. 92, 893-903 (2016)

19. Tong, W., Somasundaram, K., Birgersson, E., Mujumdar, A.S., Yap, C.: Numerical investigation of water cooling for a lithiumion bipolar battery pack. Int. J. Therm. Sci. 94, 259-269 (2015) 
20. Lan, C., Xu, J., Qiao, Y., Ma, Y.: Thermal management for high power lithium-ion battery by minichannel aluminum tubes. Appl. Therm. Eng. 101, 284-292 (2016)

21. Xu, J., Lan, C., Qiao, Y., Ma, Y.: Prevent thermal runaway of lithium-ion batteries with minichannel cooling. Appl. Therm. Eng. 110, 883-890 (2017)

22. An, Z., et al.: Experimental investigation on lithium-ion battery thermal management based on flow boiling in mini-channel. Appl. Thermal Eng. 117, 534-543 (2017)

23. Hallaj, S., Selman, J.R.: A novel thermal management system for electric vehicle batteries using phase-change material. J. Electrochem. Soc. 147(9), 3231 (2000)

24. Al-Hallaj, S., Selman, J.R.: Thermal modeling of secondary lithium batteries for electric vehicle/hybrid electric vehicle applications. J. Power Sources 110(2), 341-348 (2002)

25. Rao, Z., Wang, S., Zhang, G.: Simulation and experiment of thermal energy management with phase change material for ageing $\mathrm{Li}$ $\mathrm{FePO}_{4}$ power battery. Energy Convers. Manag. 52(12), 3408-3414 (2011)

26. Khateeb, S.A., Farid, M.M., Selman, J.R., Al-Hallaj, S.: Design and simulation of a lithium-ion battery with a phase change material thermal management system for an electric scooter. J. Power Sources 128(2), 292-307 (2004)

27. Sabbah, R., Kizilel, R., Selman, J.R.: Active (air-cooled) vs. passive (phase change material) thermal management of high power lithium-ion packs: limitation of temperature rise and uniformity of temperature distribution. J. Power Sources 182, 630-638 (2008)

28. Ling, Z., et al.: Experimental and numerical investigation of the application of phase change materials in a simulative power batteries thermal management system. Appl. Energy 121, 104-113 (2014)

29. Li, W.Q., Qu, Z.G., He, Y.L., Tao, Y.B.: Experimental study of a passive thermal management system for high-powered lithium ion batteries using porous metal foam saturated with phase change materials. J. Power Sources 255, 9-15 (2014)

30. Wang, Z., Zhang, Z., Jia, L., Yang, L.: Paraffin and paraffin/ aluminum foam composite phase change material heat storage experimental study based on thermal management of Li-ion battery. Appl. Therm. Eng. 78, 428-436 (2015)

31. Kokam Co. Ltd.: KOKAM Li-ion/polymer cell superior lithium polymer battery (SLPB), pp. 1-5. Kokam Co. Ltd (2016)

32. Chen, Y., James, W.E.: Three-dimensional thermal modeling of lithium-polymer batteries under galvanostatic discharge and dynamic power profile. J. Electrochem. Soc. 141(11), 2947 (1994)

33. Frasis: Frasis IMP06160230P25A Datasheet, p. 1. Frasis Energy Ltd (2011)

34. XALT.: XALT-37Ah Ultra High Power (UHP) Lithium-Ion Cell, vol. 1, p. 1 (2017)

35. EiG: ePLB C-high energy product. Energy Innovation Ltd. http:// www.eigbattery.com/_eng/developer/m_product_data_set $/ \mathrm{m}_{\text {_ }}$ index.asp (2016)

36. Lin, P., Zhua, Q., Jin, M. G.: Tenergy-Product Specification 30123. Tenergy corporation. vol. 21, pp. 1-7 (2008)
37. Targray: High-performance Li-ion cells for batteries and energy storage systems Targray. Energy Ltd, vol 1, p. 1. https://www.targr ay.com/li-ion-battery/lithium-ion-cells (2016)

38. Fathabadi, H.: High thermal performance lithium-ion battery pack including hybrid active-passive thermal management system for using in hybrid/electric vehicles. Energy 70, 529-538 (2014)

39. Bai, F., Chen, M., Song, W., Feng, Z., Li, Y., Ding, Y.: Thermal management performances of PCM/water cooling-plate using for lithium-ion battery module based on non-uniform internal heat source. Appl. Therm. Eng. 126, 17-27 (2017)

40. Rambaldi, L., Bocci, E., Orecchini, F.: Preliminary experimental evaluation of a four wheel motors, batteries plus ultracapacitors and series hybrid powertrain. Appl. Energy 88(2), 442-448 (2011)

41. Young, K., Wang, C., Wang, L.Y., Strunz, K.: Electric Vehicle Integration into Modern Power Networks, p 15-56. Springer, New York (2013)

42. Javani, N., Dincer, I., Naterer, G.F., Yilbas, B.S.: Heat transfer and thermal management with PCMs in a Li-ion battery cell for electric vehicles. Int. J. Heat Mass Transf. 72, 690-703 (2014)

43. Harikrishnan, S., Kalaiselvam, S.: Experimental investigation of solidification and melting characteristics of nanofluid as PCM for solar water heating systems. Int. J. Emerg. Technol. Adv. Eng. 3, 628-635 (2013)

44. Silakhori, M., Naghavi, M.S., Metselaar, H.S.C., Mahlia, T.M.I., Fauzi, H., Mehrali, M.: Accelerated thermal cycling test of microencapsulated paraffin wax/polyaniline made by simple preparation method for solar thermal energy storage. Materials (Basel) 6(5), 1608-1620 (2013)

45. Ukrainczyk, N., Kurajica, S., Šipušiæ, J.: Thermophysical comparison of five commercial paraffin waxes as latent heat storage materials. Chem. Biochem. Eng. Q4(2), 129-137 (2010)

46. Montgomery, D.: Introduction to Statistical Quality Control, p. 1-734. John Wiley \& Sons, Inc (2012)

47. Granato, D., de Araújo Calado, V.M.: The use and importance of design of experiments (DOE) in process modelling in food science and technology. In: Granato, D., Ares, G. (eds.) Mathematical and Statistical Methods in Food Science and Technology, pp. 1-18. John Wiley \& Sons (2013)

48. Hémery, C.-V., Pra, F., Robin, J.-F., Marty, P.: Experimental performances of a battery thermal management system using a phase change material. J. Power Sources 270, 349-358 (2014)

49. Ling, Z., Wang, F., Fang, X., Gao, X., Zhang, Z.: A hybrid thermal management system for lithium ion batteries combining phase change materials with forced-air cooling. Appl. Energy 148, 403-409 (2015)

Publisher's Note Springer Nature remains neutral with regard to jurisdictional clams in published maps and institutional affiliations. 